suchungen (an denen mich zu betheiligen ich bemüht sein werde) bedarf, um jene eigentliche polymere Modification der hydroschwefligen und dithionigen Săure mit vollem Rechte aus dem Gebiete des Existirenden streichen zu kōnnen.

Boch a m im November 1879.

\title{
Nachschrift über die Natur der Brenzterebin-
}

\author{
säure ; \\ von Jul. Bredt und R. Fittig.
}

Bei der Fortsetzung unserer Untersuchung über die Der:vate der Brenzterebinsäure führten uns einige neue Beobachtungen, auf welche wir hier noch nicht näher eingelien wollen, dazu, die Brenzterebinsäure selbst etwas genauer ins Auge zin fassen. Dabei hat sich dann das nach den früheren Angaben ganz unerwartete Resultat ergeben, dafs das, was man bislang als Brenztereninsäure bezeichnet hat, $d$. h. das Product der trockenen Destillation der Terebinsäure, trotz des consianten Siedepunkts, ein Gemenge und im Wesentlichen gar keine Säure, sondern das im Vorstehenden beschriebene Lacton ist.

Wir haben $10 \mathrm{~g}$ des durch langsame Destillation von reiner Terebinsäure erhaltenen und durch einmalige Rectification von etwas mit übergegangener Terebinsäure befreiten,

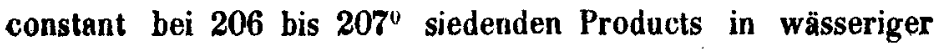
Lösung mit überschüssigem kohlensauren Calcium auf dem Wasserbade bis zur neutralen Reaction digerirt, dann filtrirt und das Filtrat destillirt. Aus dem neutral reagirenden Destillat liefsen sich mit kohlensaurem Kalium direct über $6 \mathrm{~g}$ des Lactons als Oelschicht abscheiden. Der Destillationsrückstand 
260 Bredt u. Fittig, üb. d. Natur der Brenzterebinsäure. hinterliefs nach dem voliständigen Verdunsten und Trocknen bei $100^{\circ}$ nur $2,3 \mathrm{~g}$ eines gut krystallisirenden Calciumsalzes, aus welchem Salzsäure eine ölige Säure abscheidet, die in Wasser viel weniger löslich ist, als das Lacton.

Nach diesem Versuch enthält das Product der trockenen Destillation der Terebinsäure nur $19,5 \mathrm{pC}$. Säure und $81,5 \mathrm{pC}$. des indifferenten Lactons.

Wir betalten uns vor, über die Eigenschaften und das chemische Verhalten der wirklichen Brenzterebinsäure nach Abschlufs unserer Untersuchung ausführlich 20 berichten. Die Schlüsse, zu welchen die im Vorstehenden beschriebenen Versuche führten, bedürfen jetzt natürlich der Bestätigung, aber nach einer Anzahl neverer Versuche halten wir es für sehr wahrscheinlich, dafs sie sich als richtig erweisen werden. Es wird jetzt gewifs gelingen, die Additionsproducte der Brenzterebinsäure in gröfserer Quantität darzustellen und wir zweifeln vicht daran, dafs die Bromwasserstoffverbindung mit Wasser in das Lacton übergehen wird.

Mehrere der Beobachtungen von Mielck (diese Annalen 18(D, 45), die bisher nicht verständlich waren, finden jetzt in einfachster Weise ihre Erklärung. Seine Brenzlerebinsäure war im Wesentlichen das Lacton, ja er hat sogar das ganz reine Lacton schon unter Händen gehabt. Es gelang ihm, durch starke Abkühlung und Rühren seine vermeintliche Brenzterebinsäure zum Erstarren zu bringen. Die abgeprefste Verbindung schmolz bei +5 bis $+6^{0}$. Dieser feste Körper war das Lacton, welches in reinem Zustande schon bei $0^{\circ}$ leicht erstarrt und bei 7 bis $8^{0}$ wieder schmilzt.

Strafsburg, den 6. December 1879. 